\title{
Treadmill exercise test in short children
}

\author{
C DE SAN LAZARO, J M PARKIN, AND S J TURNER \\ Children's Day Unit, Royal Victoria Infirmary, Newcastle upon Tyne
}

SUMMARY Fifty nine children of short stature exercised for 10 minutes on a non-motorised treadmill. In 49 a growth hormone concentration of greater than $15 \mathrm{mU} / \mathrm{l}$ was reached, effectively excluding growth hormone deficiency. In 10 children the growth hormone concentration failed to reach $15 \mathrm{mU} / \mathrm{l}$; growth hormone deficiency was confirmed in seven by a subsequent insulin tolerance test. The optimal time for blood sampling was five minutes after the end of the exercise. It was possible to use the test for very young and very short children.

Physical exercise is a well known stimulus to growth hormone secretion. Buckler, in 1973, first proposed a standardised test for children-10 minutes exercise on a bicycle ergometer to produce mild exhaustion and tachycardia, with blood samples taken 25 minutes after exercise. ${ }^{1} \mathrm{~A}$ similar protocol is recommended by the Health Services Human Growth Hormone Committee, ${ }^{2}$ and many growth centres throughout Britain use exercise stress as an initial test. There is, however, great variation in the methods used and in the success rates reported, the latter varying from a very poor $40 \%$ to $87 \%$. ${ }^{3}$

The use of the static bicycle ergometer has the advantage that it is attractive to children when they can manipulate it well. It has the disadvantage, however, that it is impossible for very short and very young children to use,${ }^{4}$ and it is for these that the need for an effective, safe outpatient test is most important. We, therefore, have used a non-motorised treadmill for testing growth hormone response to exercise and present the results in this paper.

\section{Patients and methods}

Fifty nine children underwent the test; there were 37 boys and 22 girls, with ages ranging from 3 to 17 years. All had been referred to the growth clinic with short stature, and in most the height was well below the third centile. Ten had been reported to have low concentrations of growth hormone after exercise or sleep before referral.

There was no preparation for the test and for most patients it was done towards the end of the morning. An intravenous cannula was usually in-

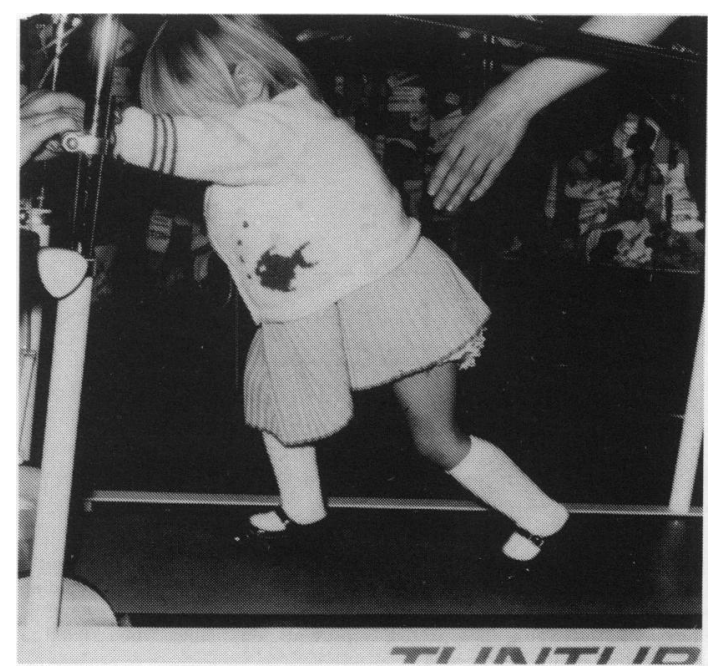

Fig. 1 The treadmill in use.

serted before the start of the exercise. Each child exercised on the treadmill (the Tunturi Jogger, Fig. 1) for 10 minutes and was asked to move the belt at a speed of at least five kilometres per hour for the whole period. The first five minutes of exercise was performed against the resistance of maximum brake but this was removed for the second five minutes.

Most children under the age of 6 years were unable to move the belt. They were asked to run on the treadmill for seven minutes only, while the belt was kept moving at a speed of five kilometres an hour by a member of staff or a parent. After seven to 10 minutes the child rested in bed and blood samples were collected, five, 15 , and 25 minutes after the end of the exercise for growth hormone and other relevant investigations, for example thyroid function and chromosomes. Growth hormone concentrations were measured by radioimmunoassay.

\section{Results}

The maximum growth hormone concentration achieved in each child in relation to age is shown in Fig. 2. Forty nine children achieved growth hor- 


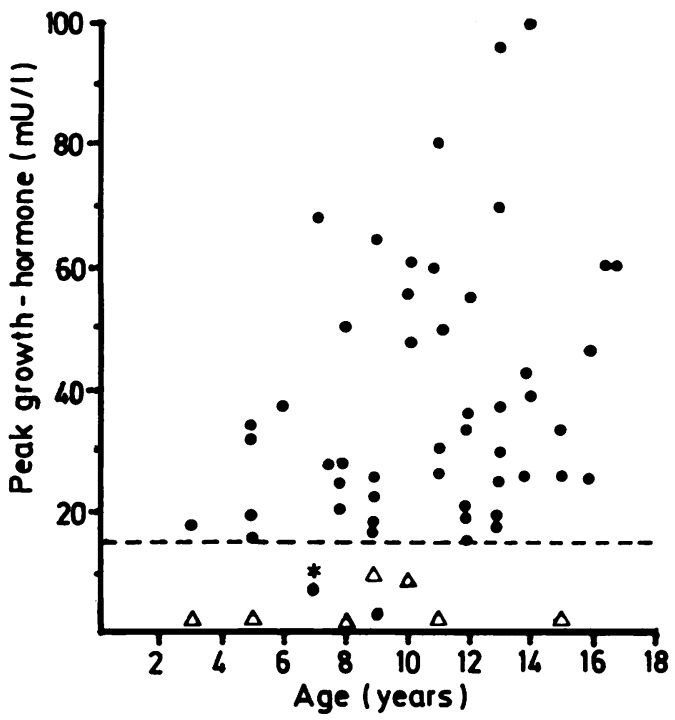

Fig. 2. Maximum growth hormone $(\mathrm{GH})$ concentration in relation to age.

Closed circles above dashed line represent children with normal GH values triangles represent 7 children who subsequently failed insulin or clonidine tests: closed circles below dashed line represent 2 children whose growth is being monitored: and the asterisk represents one child who passed a subsequent clonidine/insulin test.

mone concentrations of at least $15 \mathrm{mU} / \mathrm{l}$, and in all of these this value was reached five minutes after the end of the exercise. In 44 the maximum growth hormone concentration was found at five minutes, while in three children the highest value occurred at 15 minutes and in two at 25 minutes. Mean growth hormone concentration at the different times in children with normal growth hormone responses are shown in Fig. 3. In 10 children growth hormone concentrations at 15 minutes had fallen to below 15 $\mathrm{mU} / \mathrm{l}$ so that had samples been taken at that time only, growth hormone deficiency could not have been excluded. Similarly in 18 children concentrations at 25 minutes had fallen to below $15 \mathrm{mU} / \mathrm{l}$. This is the time interval for sampling recommended by earlier studies. ${ }^{12}$

In 10 children the maximum growth hormone was less than $15 \mathrm{mU} / \mathrm{l}$. Eight of these subsequently had an insulin tolerance test or clonidine stimulation test and seven failed to respond-maximum growth hormone concentrations being similar to those produced by the exercise stimulus. Two children (aged 7 and 9 years) have not been subjected to further testing as their growth progress is being monitored. One child, a boy of 7 years, produced a maximum response to exercise of $10.7 \mathrm{mU} / \mathrm{l}$; during a later insulin stress test the concentration was greater than $15 \mathrm{mU} / \mathrm{l}$.

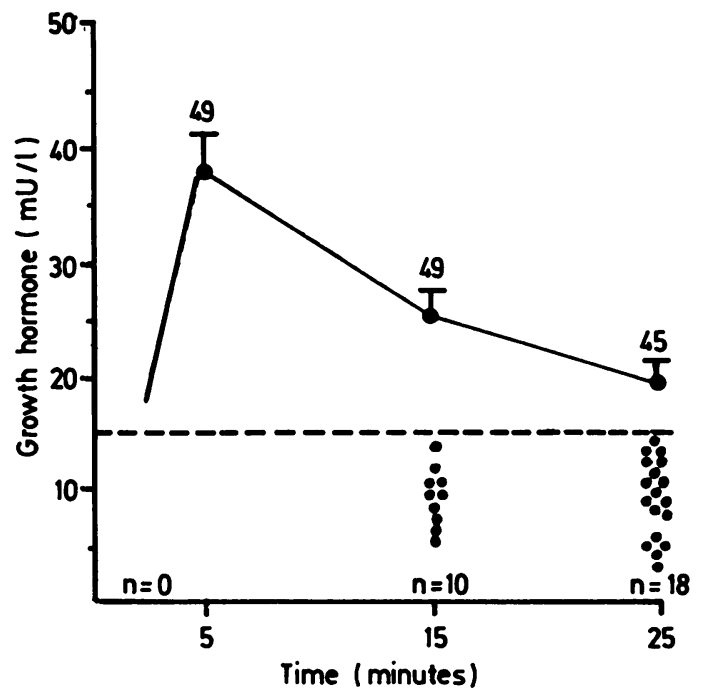

Fig. 3 Mean growth hormone concentrations and number below 15 mU/l at 5,10 , and 15 minutes after the exercise test in children with normal responses.

\section{Discussion}

Although the insulin stress test is still the standar test for the confirmation of growth hormone de. ficiency recommended by the Health Servicess Human Growth Hormone Committee, it has major disadvantages as an initial test: hypoglycaemia is unpleasant and may be dangerous; a doctor is needed at the bedside throughout the test; and as the peak response is very variable several blood samples are necessary. Our results show that exercise on the treadmill is an effective initial test. As a blood sample taken five minutes after the end of the exercise, that is 15 minutes from the beginning of the test, showed satisfactory growth hormone concentrations, the test can be performed easily in the outpatient department. The timing of the peak growth hormone response is earlier than in most previous descriptions of exercise stimulation tests but is similar to that found in healthy adults. ${ }^{3}$

We found the test appropriate for children of $D$ almost any age and size. Taller and stronger children use relatively less energy than younger children $\stackrel{N}{\circ}$ running on the belt at five kilometres per hour but this did not impair the value of the test for older children. A real advantage of the treadmill test was that it could be used for very small children; our youngest child was 3 years old and only $87 \mathrm{~cm}$ tall. Although very young children do not enjoy it as much as older children, it has proved acceptable to ? them. Since the earlier the treatment of children 
with growth hormone deficiency is begun the more effective it is, paediatricians should investigate for possible growth hormone deficiency in very young children. The treadmill exercise test is an effective, safe and practical way of doing this.

We thank Sister Linda Pearson and the staff of the Children's Day Unit for their generous assistance.

\section{References}

1 Buckler JMH. Plasma growth hormone response to exercise as diagnostic aid. Arch Dis Child 1973;48:565-7.

2 Milner RDG, Burns EL. Investigation of suspected growth hormone deficiency. Arch Dis Child 1982:57:944-7.

${ }^{3}$ Kenny T. Studies of growth hormone stimulation tests. Newcastle upon Tyne: University of Newcastle upon Tyne, BMSc. 1980.

${ }^{4}$ Lacey KA, Hewison A, Parkin JM. Exercise as a screening test for growth hormone deficiency in children. Arch Dis Child 1973;48:508-12.

Correspondence to Dr C de San Lazaro, Department of Paediatrics, Royal Victoria Infirmary, Newcastle upon Tyne NE1 4LP.

Received 2 April 1984

\section{Commentary}

\section{G D BROOK}

\section{Middlesex Hospital, London}

With the probability that growth hormone will become available in large quantities, the need to define indications for growth hormone treatment becomes more and more important and probably less and less easy. It is increasingly clear that growth hormone deficiency is not an absolute diagnosis and that relative degrees of deficiency may be clinically relevant. The short reports on tests of growth hormone secretion in this issue of the Archives are directed towards excluding classical growth hormone deficiency and, plainly, if the exercise stimulus is great enough, they can do this very adequately. The question is whether they produce clinically relevant information.

Absolute stature is not an indication for measurement of growth hormone. Only children growing at an abnormally low rate deserve a test of growth hormone secretion and far too many short children growing normally are subjected to the pain of repeated sampling, their parents to the anxiety of awaiting the results, laboratories to the trouble of making the measurements, and the National Health Service to the expense-for no good reason.

Compared with measurements of plasma growth hormone by radioimmunoassay (or indeed with any other biochemical investigation) the precision of measuring stature is formidable. In the best of hands, the coefficient of variation is less than $0.1 \%$ and, if measurements are made at successive clinic appointments by the same observer, the coefficient of variation will be comfortably within $1 \%$. It is usually not very difficult to tell over a six month period whether a child is growing normally or not and in the child who really is not growing, the answer can be obvious in as little as three months.

It is as bad medical practice to observe a child growing slowly, even if his height is still within the centiles, and not to investigate and treat him as it is to investigate a child simply for being short. Every day that passes with a poor growth velocity leads to a loss of ultimate stature. Particularly culpable in this respect are doctors who have charge of patients with malignant disease who happily administer craniospinal irradiation and chemotherapy without either keeping or using measurements of the child's stature.

\section{Who should perform tests of growth hormone secretion?}

Many of the requests for the assay of plasma growth hormone are inappropriate and most could be eliminated by the careful assessment of growth velocity and a knowledge of growth assessment. Every physician should measure the heights (and weights if he must) of the children under his care and ought to be able to detect an abnormal growth rate. When he has done so, he should not delay in finding an explanation.

Such an explanation may lie in the whole of the field of paediatric medicine; but it may include growth hormone deficiency. If this is suspected, a normal growth hormone concentration to a physiological test such as deep sleep (preferably monitored electroencephalographically) or strenuous exercise as described in the accompanying papers is probably the safest and simplest way to exclude the diagnosis. Children who seem to produce growth hormone to physiological stimuli but are apparently growth hormone deficient need further detailed endocrine assessment. As most paediatric units have insufficient practice and experience in the performance and interpretation of detailed tests of hypothalamo-pituitary function, tests such as insulin induced hypoglycaemia may be dangerous. Further, they have too often to be repeated in a tertiary referral centre because the test has not been properly conducted, sufficient samples have not been collected, or the assays used have been performed by laboratories that do not subscribe to the national quality control schemes. In the hospital in which I do not undertake specialist endocrine 